\title{
The cap binding complex influences H2B ubiquitination by facilitating splicing of the SUS1 pre-mRNA
}

\author{
MUNSHI AZAD HOSSAIN, JULIA M. CLAGGETT, TIFFANY NGUYEN, and TRACY L. JOHNSON \\ Molecular Biology Section, Division of Biological Sciences, University of California, San Diego, La Jolla, California 92093, USA
}

\begin{abstract}
Pre-messenger RNA splicing is carried out by a large ribonucleoprotein complex called the spliceosome. Despite the striking evolutionary conservation of the spliceosomal components and their functions, controversy persists about the relative importance of splicing in Saccharomyces cerevisiae-particularly given the paucity of intron-containing genes in yeast. Here we show that splicing of one pre-messenger RNA, SUS1, a component of the histone H2B ubiquitin protease machinery, is essential for establishing the proper modification state of chromatin. One protein complex that is intimately involved in premRNA splicing, the yeast cap-binding complex, appears to be particularly important, as evidenced by its extensive and unique genetic interactions with enzymes that catalyze histone H2B ubiquitination. Microarray studies show that cap binding complex (CBC) deletion has a global effect on gene expression, and for $\sim 20 \%$ of these genes, this effect is suppressed when ubiquitination of histone $\mathrm{H} 2 \mathrm{~B}$ is eliminated. Consistent with this finding of histone $\mathrm{H} 2 \mathrm{~B}$ dependent effects on gene expression, deletion of the yeast cap binding complex leads to overubiquitination of histone H2B. A key component of the ubiquitinprotease module of the SAGA complex, Sus1, is encoded by a gene that contains two introns and is misspliced when the CBC is deleted, leading to destabilization of the ubiquitin protease complex and defective modulation of cellular $\mathrm{H} 2 \mathrm{~B}$ levels. These data demonstrate that pre-mRNA splicing plays a critical role in histone $\mathrm{H} 2 \mathrm{~B}$ ubiquitination and that the CBC in particular helps to establish the proper state of chromatin and proper expression of genes that are regulated at the level of histone $\mathrm{H} 2 \mathrm{~B}$ ubiquitination.
\end{abstract}

Keywords: cap binding complex; splicing; SAGA; histone H2B ubiquitination; transcription; Saccharomyces cerevisiae

\section{INTRODUCTION}

Pre-messenger RNA splicing plays an essential role in gene expression. The majority of genes in higher eukaryotes are interrupted by noncoding intron sequences that must be removed for accurate expression of the information contained within the exons. Since most higher eukaryotic genes contain multiple introns, the alternative use of splice sites provides the opportunity for dramatic expansion of the gene expression capabilities of the cell (for review, see Matlin et al. 2005; Blencowe 2006).

In Saccharomyces cerevisiae, the role of splicing in gene expression has been more controversial due to the relative paucity of intron-containing genes $(\sim 5 \%)$ and the fact that few of these genes contain more than one intron. However,

Reprint requests to: Tracy L. Johnson, Molecular Biology Section, Division of Biological Sciences, University of California, San Diego, MC0377, 9500 Gilman Drive, La Jolla, CA 92093-0377, USA; e-mail: johnsont@ ucsd.edu; fax: (858) 822-1505.

Article published online ahead of print. Article and publication date are at http://www.rnajournal.org/cgi/doi/10.1261/rna.1540409. the few genes in yeast that do contain introns suggest a critical role for splicing in regulating the activities of key gene expression machineries. For example, the majority of intron-containing genes in yeast encode ribosomal protein genes. Hence, changes in splicing in yeast provide an opportunity to fundamentally alter translation. Consistent with this, recent data demonstrate that under environmental stress conditions, there are important shifts in splicing of genes encoding ribosomal proteins (Pleiss et al. 2007a). These data suggest that splicing allows formation of different ribosomes that may allow cells to respond to different conditions by altering their translation profile. While recent studies showing distinct functions for ribosomal protein paralogs also support a role for "specialized" ribosomes in gene expression (Komili et al. 2007), isolation of functionally distinct ribosomes has not yet been accomplished. Nonetheless, it is clear that splicing of critical genes that encode key components of the gene expression machinery could provide a way of regulating gene expression in yeast.

In the last several years, it has also become increasingly clear that histone modification is important for control of 
gene expression. The $\mathrm{N}$-terminal tails of histones undergo a variety of modifications such as acetylation, phosphorylation, and methylation. An additional modification, monoubiquitination, specifically on the tails of histones $\mathrm{H} 2 \mathrm{~A}$ and $\mathrm{H} 2 \mathrm{~B}$, has been shown to play a critical role in regulating many processes within the nucleus, including transcription initiation, elongation, and silencing (Osley et al. 2006; Weake and Workman 2008).

Histone H2B ubiquitination at lysine 123 is carried out by Rad6, the E2 ubiquitin conjugating enzyme, and its cognate E3 ubiquitin ligase, Bre1. Both Rad6 and Bre1 are recruited to promoters by transcriptional activators (Wood et al. 2003a,b; Kao et al. 2004), and Rad6 associates with the elongating form of the polymerase in a Brel- and PAFcomplex-dependent manner (Xiao et al. 2005). Furthermore, mutating the target of ubiquitination (K123R) leads to lowered transcription of particular genes (Henry et al. 2003). Rad6/Bre1-mediated H2B ubiquitination is required for H3K4 methylation and H3K79 methylation, both of which are marks of active transcription (Briggs et al. 2002; Dover et al. 2002; Ng et al. 2002; Sun and Allis 2002). There is also evidence from in vitro transcription studies of a direct role for histone $\mathrm{H} 2 \mathrm{~B}$ ubiquitination in the passage of RNA polymerase through a nucleosomal template (Pavri et al. 2006), and in vivo studies also support an H3K4independent role for $\mathrm{H} 2 \mathrm{~B}$ ubiquitination in transcription elongation through the chromatin template (Shukla and Bhaumik 2007; Tanny et al. 2007).

The level of ubiquitination of histone H2B is delicately balanced by the activity of the ubiquitinating complex and the ubiquitin specific protease, Ubp8. Ubp8 is part of the SAGA complex, and its association with SAGA is required for its activity (Lee et al. 2005). Although Ubp10 has also been implicated in H2BK123 deubiquitination, it works through a different, SAGA-independent pathway (Gardner et al. 2005). Three other components of SAGA are required for Ubp8 activity, Sgf11, Sgf73, and Sus1; and deletion of any of these genes prevents the removal of ubiquitin from H2B (Lee et al. 2005; Kohler et al. 2008).

Recently, there has been increasing evidence that the deubiquitination of histone H2B may be equally important as ubiquitination in the regulation of transcription. Deletion of UBP8 severely hampers transcription of SAGAregulated genes (Henry et al. 2003). Ubp8 and a subset of SAGA components travel with the elongating polymerase into the open reading frame of certain genes. Moreover, Ubp8 is required for recruitment of the kinase, Ctk1, which phosphorylates serine 2 of the C-terminal domain (CTD) of RNA polymerase II and is necessary for the transition from initiation to active elongation (Wyce et al. 2007). The association of both the ubiquitinating and deubiquitinating complexes with the elongating polymerase suggests a model whereby multiple rounds of ubiquitination and deubiquitination occur during transcription elongation. The importance of $\mathrm{H} 2 \mathrm{~B}$ deubiquitination has not only been demonstrated for yeast, but also extends to higher eukaryotic organisms. H2B deubiquitination controls development of the Drosophila visual system (Weake et al. 2008), flowering time in Arabidopsis (Cao et al. 2008), and expression of proto-oncogenes in human cells (Shema et al. 2008). Hence, it is important to understand how this chromatin mark is made and regulated.

Studies of the yeast cap binding complex (CBC), comprised of an $80-\mathrm{kDa}$ subunit (Cbp80) and a $20-\mathrm{kDa}$ subunit (Cbp20), have revealed an intersection between two critical steps in gene expression-pre-mRNA splicing and histone modification. The cap binding complex associates with the U1 snRNP and facilitates its recognition of the $5^{\prime}$ splice site (Colot et al. 1996; Lewis et al. 1996), as well as U1 snRNP dissociation from the spliceosome and concomitant triplesnRNP association with pre-mRNA (O'Mullane and Eperon 1998; Görnemann et al. 2005). Recently, it has also been shown that the cap binding complex is required for cotranscriptional spliceosome assembly (Görnemann et al. 2005).

While the yeast cap binding complex has previously been implicated in transcription termination by preventing termination at weak transcription termination sites (Das et al. 2000; Wong et al. 2007), other potential roles in transcription are poorly understood. For example, several years ago it was shown that a mutation in the large subunit of the $\mathrm{CBC}$ suppressed the temperature-sensitive growth defect conferred upon deletion of HPR1 (Uemura et al. 1996), a subunit of the THO/TREX complexes that couples transcription elongation with mitotic recombination (Chavez et al. 2000). Hprl is recruited to the chromatin, and its deletion leads to transcription elongation defects, transcription-dependent hyper-recombination, and synthetic interactions with several transcription elongation factors involved in chromatin modification: Pafl (Chang et al. 1999), Spt4 (Rondon et al. 2003), and Spt6 (Burckin et al.

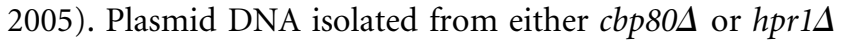
is significantly more negatively supercoiled than normal, suggesting that the $\mathrm{CBC}$ could also affect transcription elongation and chromatin (Uemura et al. 1996). Nonetheless, such a role for the $\mathrm{CBC}$ has not previously been demonstrated.

Here we show that the yeast cap binding complex affects the modification state of histone $\mathrm{H} 2 \mathrm{~B}$ by ensuring proper deubiquitination at lysine residue 123. Deletion of genes encoding either subunit of the CBC leads to a slow growth phenotype that can be partially suppressed by either a mutated histone H2B (htb1-K123R) or deletion of components of the ubiquitin ligase complex. Analysis of global gene expression by microarray demonstrates that deletion of $C B P 80$ has a global effect on expression that can be suppressed by preventing $\mathrm{H} 2 \mathrm{~B}$ ubiquitination via mutation of htb1-K123R. Accordingly, in the absence of the CBC, we observe histone $\mathrm{H} 2 \mathrm{~B}$ over-ubiquitination and misregulated expression of $A R G 1$, a gene regulated at the level of $\mathrm{H} 2 \mathrm{~B}$ ubiquitination. Deletion of the $\mathrm{CBC}$ leads to missplicing of 
SUS1, a component of the ubiquitin protease complex; enriches for a partially spliced SUS1 pre-mRNA; and leads to dramatically reduced Sus1 protein levels. The mechanism by which the $\mathrm{CBC}$ acts to contribute to regulation of $\mathrm{H} 2 \mathrm{~B}$ ubiquitination reinforces the important role of premRNA splicing in regulating fundamental gene expression reactions such as histone modification. Since the levels of the cap binding complex can have such a profound effect on $\mathrm{H} 2 \mathrm{~B}$ ubiquitination, and in light of studies demonstrating that $\mathrm{CBC}$ expression is sensitive to a variety of growth and stress conditions (Gasch et al. 2000), we posit a model whereby changes in the levels of the cap binding complex modulate the delicate balance of histone ubiquitination and deubiquitination as a crucial regulatory mechanism in the cell.

\section{RESULTS}

\section{The growth defect for strains deleted of either component of the cap binding complex is partially suppressed in the absence of H2B ubiquitination}

In order to identify possible functions for the $\mathrm{CBC}$ in transcription, we undertook a genetic analysis to identify functional interactions between the $\mathrm{CBC}$ and factors involved in transcriptional regulation. Strains deleted of either CBP80 or CBP20 were crossed to strains deleted of nonessential components of the transcription machinery. Strikingly, while deletion of either $C B P 80$ or $C B P 20$ alone results in slow growth, particularly at $25^{\circ} \mathrm{C}$, the additional deletion of BRE1 or RAD6 in these strains suppressed this growth defect (Fig. 1A). Growth suppression at $30^{\circ} \mathrm{C}$ was also apparent when the colonies resulting from tetrad dissection were compared (data not shown). Rad6 is an E2 ubiquitin ligase, and Bre1 is required for Rad6 association with H2B and with Pol II (Wood et al. 2003a). Deletion of either factor eliminated H2B ubiquitination (ub-H2B). Hence, these data suggest that inhibiting the ubiquitination of $\mathrm{H} 2 \mathrm{~B}$ suppresses the impaired growth of cells deleted of the $\mathrm{CBC}$.

To confirm that the observed suppression of the $c b c \Delta$ growth defect was due to Rad6/Brel roles in ubiquitination of their histone target, wild-type (WT) HTB1 (which encodes histone $\mathrm{H} 2 \mathrm{~B}$ ) was replaced with a mutated allele that could not be ubiquitinated (htb1-K123R), and this mutation was analyzed in cells lacking CBP80 and CBP20. While the inability of $\mathrm{H} 2 \mathrm{~B}$ to be ubiquitinated had almost no effect on the growth of WT strains (Fig. 1B, top), the growth defect of $\operatorname{cbp} 80 \Delta$ was suppressed at both $25^{\circ} \mathrm{C}$ and $30^{\circ} \mathrm{C}$ (Fig. 1B, middle). Thus, even if Rad6 and Bre1 have nonhistone targets, this result confirms that it is their function in the H2B ubiquitin ligase complex that counters the deleterious effects of deleting CBP8O.

Microarray analysis of $c b p 80 \Delta$ and $c b p 20 \Delta$ suggests that the two factors have distinct functions in gene expression
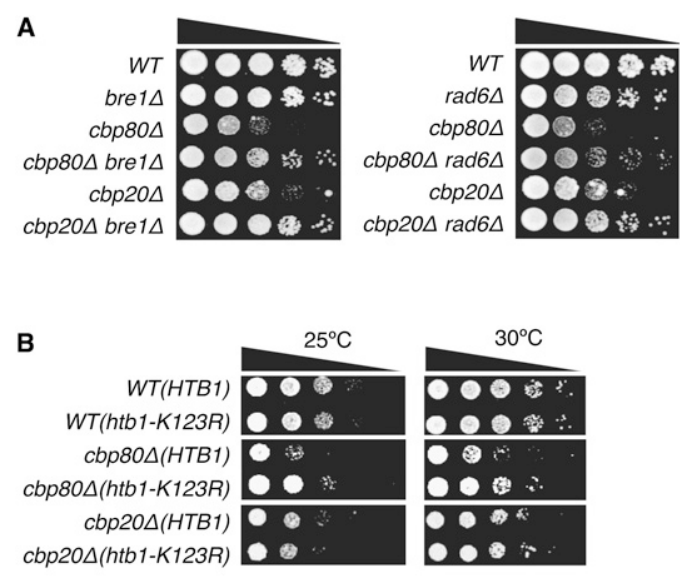

C

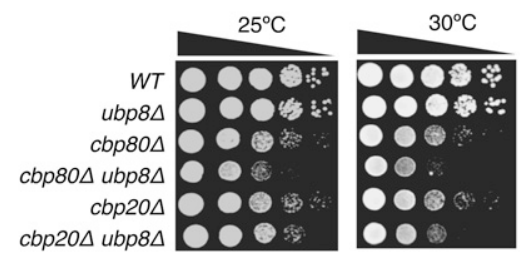

FIGURE 1. The growth defect of $c b p 80 \Delta$ and $c b p 20 \Delta$ is suppressed in the absence of $\mathrm{H} 2 \mathrm{~B}$ ubiquitination and exacerbated upon deletion of the deubiquitinase, UBP8. Cultures of the strains indicated were grown to the same optical density, serially diluted in 10-fold increments, and spotted in equal volumes. (A) Strains were spotted onto YPD plates and grown for $3 \mathrm{~d}$ at $25^{\circ} \mathrm{C}$. (B) Cells deleted of $H T B 1$, but containing plasmid Flag-HTB1 or Flag-htb1-K123 as indicated, were spotted onto SC medium lacking histidine and grown at the indicated temperatures for either $2 \mathrm{~d}(\mathrm{WT})$ or $4 \mathrm{~d}(\operatorname{cbc} \Delta)$. (C) Strains were spotted onto YPD plates and grown for $3 \mathrm{~d}$ at the indicated temperatures.

outside of their joint role in splicing (Burckin et al. 2005; JM Claggett and TL Johnson, unpubl.), which may explain the more modest suppression by $h t b 1-K 123 R$ of the $c b p 20 \Delta$ growth defect. Nonetheless, the genetic interactions we observed for $c b p 80 \Delta$ indicate that the $\mathrm{CBC}$ affects the levels of $\mathrm{H} 2 \mathrm{~B}$ ubiquitination in a way that counters the effect of the H2B ubiquitin ligase complex. These results also demonstrate that this effect on chromatin is an important part of the CBC's function in the cell, since viability of the $\mathrm{CBC}$ deleted cell can be partially restored by altering levels of the H2B modification.

Ubp8 is a component of the SAGA complex and functions as the deubiquitinase for histone H2B (Lee et al. 2005). Since the results above demonstrate that in the absence of the genes encoding the $\mathrm{CBC}$, removing $\mathrm{H} 2 \mathrm{~B}$ ubiquitination improves cell growth, it was suspected that increasing the levels of $\mathrm{H} 2 \mathrm{~B}$ ubiquitination by deleting $U B P 8$ would confer the opposite effect. We analyzed this in strains deleted of either $C B P 80$ or $C B P 20$ and found that deletion of UBP8 exacerbates the $c b c \Delta$ growth defect, as expected (Fig. 1C), indicating that the CBC and Ubp8 may work synergistically to perform their cellular functions.

Collectively, the genetic interactions between the $\mathrm{CBC}$ and the $\mathrm{H} 2 \mathrm{~B}$ ubiquitin regulating machineries suggest that 
the $\mathrm{CBC}$ plays a role in maintaining the proper balance of ub-H2B.

\section{Deletion of the CBC leads to altered expression of a large number of genes, which can be suppressed by abrogating H2B ubiquitination}

The state of H2B ubiquitination has global effects on gene expression (Mutiu et al. 2007). If the CBC plays a role in regulating ub- $\mathrm{H} 2 \mathrm{~B}$, deletion of the CBC should likewise cause widespread changes in gene expression. By microarray analysis, we compared the expression profile of a $c b p 80 \Delta$ strain to that of a wild-type strain grown in rich media at $30^{\circ} \mathrm{C}$. We observed a twofold or greater change in expression upon deletion of CBP80 for a large number of genes (369 genes total) (data not shown).

Given the role of the CBC in splicing, it was not surprising that introncontaining genes were significantly overrepresented $(p \ll 0.001)$ in the set of genes whose expression decreased in the absence of the CBC (data not shown). Notably, a larger number of intronless genes showed an increase in expression in the absence of the $\mathrm{CBC}$, a trend that was also observed in the absence of Ubp8, the H2B deubiquitinase. In these Ubp8 studies, changes in expression of the 30 genes most significantly affected by UBP8 deletion are suppressed when $\mathrm{H} 2 \mathrm{~B}$ is additionally mutated (ubp8shtb1-K123R), confirming that Ubp8 affects gene expression by regulating $\mathrm{H} 2 \mathrm{~B}$ ubiquitination (Mutiu et al. 2007). With a similar trend in global changes to gene expression for $c b p 80 \Delta$ and $u b p 8 \Delta$ and an indication from the genetics data that the two factors work synergistically, we hypothesized that it would be possible to identify genes whose change in expression upon $C B P 80$ deletion was $\mathrm{H} 2 \mathrm{~B}$ dependent since this expression change should likewise be suppressed by $h t b 1-K 123 R$. Hence, the microarray analysis was expanded to include a $c b p 80 \Delta$ strain in which $\mathrm{H} 2 \mathrm{~B}$ was additionally mutated (Fig. 2, cbp80A htb1K123R). A CBP80 WT strain with the same mutation was included as a control (Fig. 2, htb1K123R). In all strains used for these analyses, native $H T B 1$ was replaced with a Flag-tagged version of either HTB1 or $h t b 1-K 123 R$ expressed from a plasmid. Although expression of this plasmid does not appear to affect the phenotypic behavior of the strains, an untransformed WT strain was included in the arrays to identify and remove any genes for which expression was significantly altered by the presence of the plasmid. This analysis revealed that the change in expression for $19 \%$ of genes significantly affected by $c b p 80 \Delta$ was suppressed twofold or more by additionally mutating $\mathrm{H} 2 \mathrm{~B}\left[\mid \log _{2}(\operatorname{cbp} 80 \Delta / \mathrm{WT})-\right.$ $\left.\log _{2}(\operatorname{cbp} 80 \Delta h t b 1 K 123 R / \mathrm{WT}) \mid \geq 1.0 ; n=70\right]$ (Fig. 2), suggesting that the $\mathrm{CBC}$ has global effects on gene expression that are $\mathrm{H} 2 \mathrm{~B}$ dependent.

There is a small subset of genes $(n=28)$ for which the change in expression rendered by $c b p 80 \Delta$ and $h t b 1-K 123 R$ alone is strongly exacerbated when the mutations are combined (data not shown), suggesting that the $\mathrm{CBC}$ has other effects on chromatin that are distinct from but overlap with its effects on $\mathrm{H} 2 \mathrm{~B}$ ubiquitination. Research in progress supports this hypothesis (see Discussion).

\section{The cap binding complex regulates $A R G 1$ expression in a manner similar to other proteins that control H2B overubiquitination}

In order to confirm that deletion of the $\mathrm{CBC}$ affects expression of a gene that has been previously characterized as regulated at the level of $\mathrm{H} 2 \mathrm{~B}$ ubiquitination and deubiquitination, we analyzed the expression of ARG1 
under arginine-repleted and arginine-starved (data not shown) conditions. ARG1 is induced when cells are grown in media lacking arginine (SC-Arg); but in YPD, the expression of ARG1 is repressed (Turner et al. 2002). Both induction and repression of $A R G 1$ expression are tightly regulated by $\mathrm{H} 2 \mathrm{~B}$ ubiquitination. Cells deleted of either RAD6 or BRE1 or containing the htb1-K123R mutation are unable to repress $A R G 1$ expression in rich media (Turner et al. 2002; Lee et al. 2005). In the absence of the genes encoding Ubp8 or Sgf11, ARG1 is "overrepressed" relative to WT (Turner et al. 2002; Lee et al. 2005). Therefore, $A R G 1$ expression levels correlate with the status of ub-H2B in the cell, which is determined by the combined activities of the $\mathrm{H} 2 \mathrm{~B}$ ubiquitin ligase and deubiquitinating complexes. To determine if the deletion of the $\mathrm{CBC}$ also leads to misregulation of $A R G 1$ repression, both $\operatorname{cbp} 20 \Delta$ and cbp80A were grown in SC-Arg media and shifted to rich media (YPD), and the ARG1 transcript was analyzed by Northern blotting. ARG1 expression was more repressed in both $c b p 20 \Delta$ and $\operatorname{cbp} 80 \Delta$ than in WT cells (Fig. 3A, lanes $1,2,3$; Fig. 3B) in a manner comparable to ubp $8 \Delta$ (Fig. 3A, lanes 2,3,4; Fig. 3B). We also observed a loss of repression of ARG1 expression when RAD6 was deleted as has been previously reported (Fig. 3A, lane 7; Fig. 3B; Lee et al. 2005). When $A R G 1$ expression was examined in the double mutants, $c b p 20 \Delta u b p 8 \Delta$ and $c b p 80 \Delta u b p 8 \Delta$, under repressive conditions (growth in YPD), we observed no signifi-
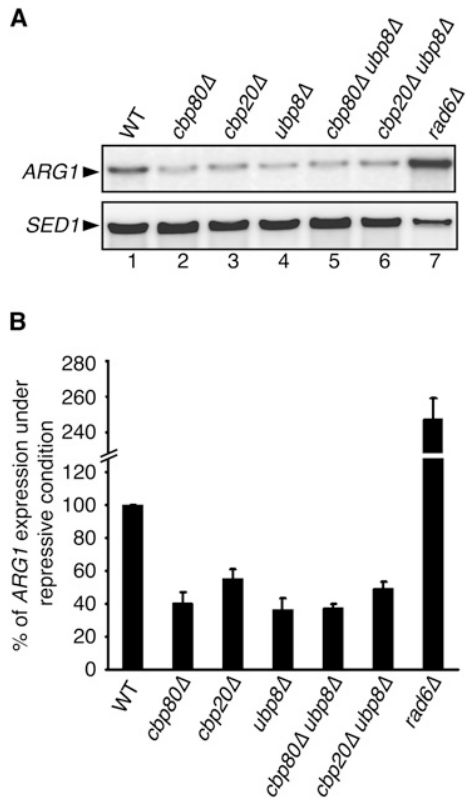

FIGURE 3. Deletion of the cap binding complex affects levels of ARG1 expression. (A) Northern blot analysis shows repression of ARG1 expression in different mutants compared with WT. SED1 mRNA serves as a loading control. (B) Quantitative analysis of ARG1 expression is presented as a bar diagram. Each bar represents the average of three independent experiments, and error bars represent the standard errors of the mean. cant change in $A R G 1$ repression in the double mutants compared with the single mutants $\operatorname{cbp} 80 \Delta, \operatorname{cbp} 20 \Delta$, and ubp $8 \Delta$ (Fig. 3A,B). Therefore, despite the synergistic growth defect caused by combining deletion of either gene encoding the $\mathrm{CBC}$ with deletion of $U B P 8$, these data demonstrate that there is no synergistic effect on ARG1 repression, suggesting that these factors may work in the same pathway to control ARG1 transcription.

$A R G 1$ expression was also analyzed in the double mutant cbp80 $\Delta$ rad64. ARG1 repression is severely inhibited such that $A R G 1$ expression is higher than WT, comparable to (or slightly higher than) deletion of RAD6 alone (data not shown). Hence, although Rad6 and Cbp80 appear to act antagonistically (Fig. 1), loss of $\mathrm{H} 2 \mathrm{~B}$ ubiquitination cannot be rescued by deletion of the CBC. Since the H2B ubiquitination machinery (Rad6/Bre1) works upstream of deubiquitination, these data suggest that Cbp80 is involved in deubiquitination. These data also reinforce the idea that both ubiquitination and deubiquitination are necessary to restore the WT level of $A R G 1$ expression.

We have also analyzed $A R G 1$ expression in $\operatorname{cbp} 20 \Delta$ and cbp80 $\Delta$ mutants under inducing conditions. We observe little change in the ARG1 transcript level in cbp20D and cbp80A compared with WT (data not shown); hence, the lowered ARG1 transcript levels in CBC mutants under repressive conditions cannot be simply attributed to a decrease in the stability of the transcript in the absence of the CBC.

These results illustrate that the cap binding complex, and particularly its effect on ub-H2B, plays an important role in a cell's ability to respond to changes in the environment. Furthermore, these results indicate that the role of the CBC in ARG1 expression is likely mediated through the same pathway as Ubp8.

\section{Deletion of the CBC causes an increase in global levels of histone $\mathrm{H} 2 \mathrm{~B}$ ubiquitination}

The finding that complete inhibition of $\mathrm{H} 2 \mathrm{~B}$ ubiquitination suppresses the $c b c \Delta$ growth defect strongly suggested that the absence of the $\mathrm{CBC}$ affects levels of $\mathrm{H} 2 \mathrm{~B}$ ubiquitination in a way that opposes the activity of the $\mathrm{H} 2 \mathrm{~B}$ ubiquitin ligase complex. To test this, the $c b p 80 \Delta$ and $c b p 20 \Delta$ strains were transformed with a Flag-tagged version of either WT HTB1 or $h t b 1-K 123 R$, and immunoblotting was performed to assess how the absence of the CBC affects the steadystate levels of ubiquitinated H2B. Deletion of CBP80 or $C B P 20$ resulted in an increase in global levels of ubiquitinated H2B (Fig. 4A). In fact, the increase observed in either mutant was comparable to that observed upon deletion of the deubiquitinase, UBP8 (Fig. 4A). As has been reported by others, deletion of either RAD6 (Fig. 4A, lane 6) or BRE1 (Fig. 4D, lane 5), or mutating the target of $\mathrm{H} 2 \mathrm{~B}$ ubiquitination (Fig. 4A, lane 1), eliminated ub-H2B (Robzyk et al. 2000). In order to quantitate the increase in ub-H2B in cells lacking either component of the $\mathrm{CBC}$, the endogenous gene 
A

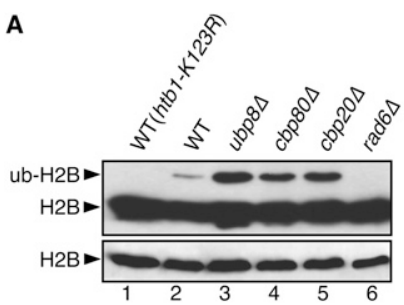

B

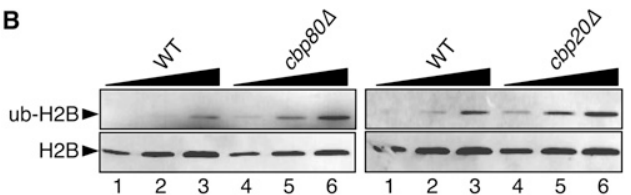

C
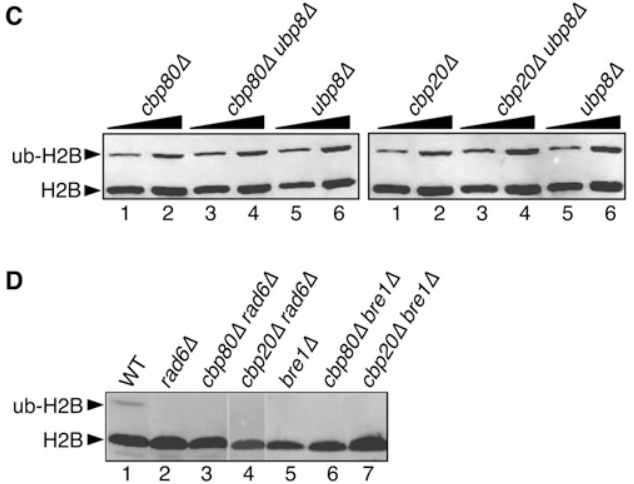

FIGURE 4. The $\mathrm{CBC}$ negatively regulates $\mathrm{H} 2 \mathrm{~B}$ ubiquitination. $(A)$ $C B P 80, C B P 20, U B P 8$, and $R A D 6$ were individually deleted from yeast strains bearing a Flag-tagged copy of either HTB1 or $h t b 1-K 123 R$, as indicated. Whole-cell extracts were prepared from equivalent cell numbers for each strain and evaluated by Western blot analysis using anti-Flag antibody. A shorter exposure of the blot shown in the upper panel is shown (lower panel) to show equal H2B loading for each strain. (B) CBP8O and CBP2O were deleted from a yeast strain in which native $H T B 1$ was replaced with a Flag-tagged copy of the gene on a plasmid. Whole-cell extracts were prepared from the strains and evaluated as above. Increasing loading amounts are shown to facilitate comparison of ub-H2B levels at equivalent levels of H2B. (C) Whole cell extracts were prepared from the strains containing native HTB1 and evaluated as above. $(D)$ Whole cell extracts were prepared and evaluated as above. Native HTB1 was replaced with a Flag-tagged copy of the gene on a plasmid.

encoding $\mathrm{H} 2 \mathrm{~B}$ was deleted so that the Flag-tagged HTB1 was the only source of functional $\mathrm{H} 2 \mathrm{~B}$ in the cell and serial twofold dilutions of cell extract were analyzed by Western blot. When levels of ub-H2B were normalized to total H2B, there was a fivefold increase in $c b c \Delta$ cells when compared with WT cells (Fig. 4B). These data indicate that the CBC negatively regulates $\mathrm{H} 2 \mathrm{~B}$ ubiquitination by either inhibiting the addition of ubiquitin to $\mathrm{H} 2 \mathrm{~B}$ or by reinforcing deubiquitination, similar to Ubp8. Based on the data described in Figure 3, we favored the latter, but wanted to test this more directly.

In an effort to discern whether the $\mathrm{CBC}$ and the deubiquitinase, Ubp8, act in the same or parallel pathways, levels of ub-H2B were analyzed in a strain deleted of either of the genes encoding the $\mathrm{CBC}$ and UBP8. $\mathrm{H} 2 \mathrm{~B}$ ubiquiti- nation did not increase further upon deletion of UBP8 in the absence of the $\mathrm{CBC}$ (Fig. 4C), arguing against an additive activity of $\mathrm{CBC}$ and $\mathrm{Ubp} 8$ and suggesting that these proteins work in the same pathway. Furthermore, deletion of the genes encoding the CBC combined with rad $6 \Delta$, bre $1 \Delta$, or $h t b 1-K 123 R$ did not show any $\mathrm{H} 2 \mathrm{~B}$ ubiquitination (Fig. 4D), indicating that deletion of the CBC does not bypass the requirement for Rad6 or Bre1 by using another ubiquitin ligase complex; nor does it stimulate ubiquitination of $\mathrm{H} 2 \mathrm{~B}$ at a residue other than $\mathrm{K} 123$. These results are consistent with the $A R G 1$ expression data and support a model in which the CBC helps to negatively regulate $\mathrm{H} 2 \mathrm{~B}$ ubiquitination, possibly by contributing to the function of Ubp8.

\section{The cap binding complex affects the steady-state level of Sus1 and Sgf11 proteins}

Two ways that the CBC could contribute to the function of Ubp8 are by affecting the expression of a component of the ubiquitin protease machinery or the targeting of these proteins to genes during active transcription. To distinguish between these possibilities, we analyzed protein levels of a tagged version of Ubp8 and its associated proteins Sus1 and Sgf11, by Western blot analysis of whole cell extract.

While we observed no significant change in the protein levels of Ubp8-TAP in $c b p 20 \Delta$ and $c b p 80 \Delta$ strains compared with WT (Fig. 5A, upper panel), Sus1 and Sgf11
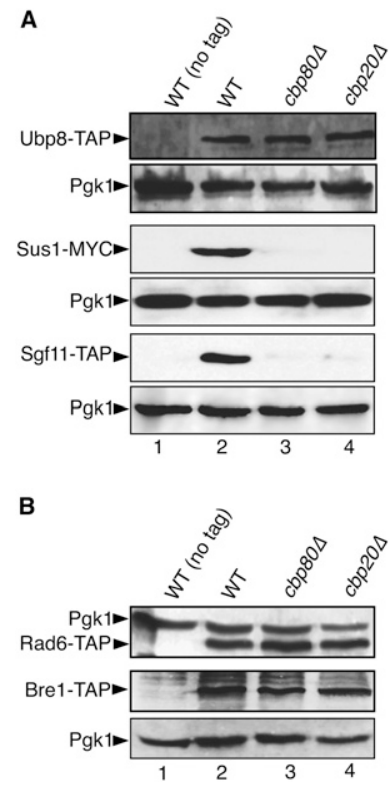

FIGURE 5. Deletion of the CBC leads to decreased levels of Suslp and Sgf11p. (A) Western blot analysis was performed to investigate the protein levels of Ubp8, Sus1, and Sgf11 in $\operatorname{cbp} 80 \Delta$ and $\operatorname{cbp} 20 \Delta$ strains compared with WT. In all the cases, Pgk1 serves as a loading control, and a WT strain (without tagged proteins) serves as a negative control for tagged protein detection. $(B)$ The protein levels of Rad6 and Brel were analyzed as above. 
protein levels were greatly decreased (Fig. 5A, middle and lower panels). Studies by others have shown that deletion of Sgf11 prevents the association of Sus1 with Ubp8 but has no effect on the expression of either factor (Kohler et al. 2008). Since deleting the CBC affects the expression of both Sgf11 and Sus1, we hypothesized that the decrease in Sgf11 protein was caused by the decrease in Sus1 protein and a concomitant destabilization of the complex. This was confirmed by deleting the gene encoding Sus1, which alone led to a complete loss of the Sgf11 protein (data not shown). We also determined the protein levels of Rad6 and Bre1 and observed no significant change in the $\operatorname{cbp} 20 \Delta$ and cbp80 $\Delta$ strains compared with WT (Fig. 5B). Recent in vitro studies have shown that the deubiquitinase activity of Ubp8 requires all the components (e.g., Sus1, Sgf11, Sgf73) of the ubiquitin protease module (Lee et al. 2005; Kohler et al. 2008). Hence, the CBC's effect on overubiquitination is likely due to its negative effect on levels of Sus1 and Sgf11 proteins.

\section{Splicing of SUS1 pre-mRNA is defective in the absence of the $\mathrm{CBC}$ and a subset of splicing factors}

The SUS1 gene contains two introns. The first intron has a nonconsensus $5^{\prime}$ splice site (Fig. 6A, GTATGA) and a nonconsensus branchpoint sequence (Fig. 6A, TACTGAC). Given that the $\mathrm{CBC}$ facilitates efficient recognition of the cap proximal 5' splice site by the U1 snRNA (Lewis et al. 1996; Gornemann et al. 2005) and has also been implicated in rearrangements that contribute to branchpoint sequence recognition (O'Mullane and Eperon 1998), we predicted that SUS1 splicing would be particularly sensitive to the activity of the cap binding complex. Moreover, SUS1 missplicing in the absence of CBP80 or CBP2O could explain the reduced levels of Sus1p in these strains. To test this possibility, total RNA was isolated from $c b c \Delta$ strains, and RT- PCR was performed to analyze the SUS1 splicing products. In the absence of either $C B P 80$ or $C B P 20$, the amount of fully spliced SUS1 mRNA decreased relative to WT (Fig. 6B, bottom band). Interestingly, while the amount of unspliced SUS1 pre-mRNA increased some for $c b p 80 \Delta$ and $c b p 20 \Delta$ (Fig. 6B, top band), we observed a much greater increase of a partially spliced SUS1 product (Fig. 6B, middle band). When this band was extracted from the gel, cloned, and sequenced, it was apparent that only the partially spliced product containing the first intron accumulates, indicating that the downstream intron is spliced normally.

To test the specificity of this splicing defect, splicing of SUS1 pre-mRNA was examined in strains deleted of other factors known to be involved in splicing. The selected splicing factors have all been shown to interact with the CBC physically: Nam8 (Gavin et al. 2006; Collins et al. 2007), Mud2 (Fortes et al. 1999), Prp5 (Oeffinger et al. 2007), and Lea1/Msl1 (Collins et al. 2007); or genetically: Nam8
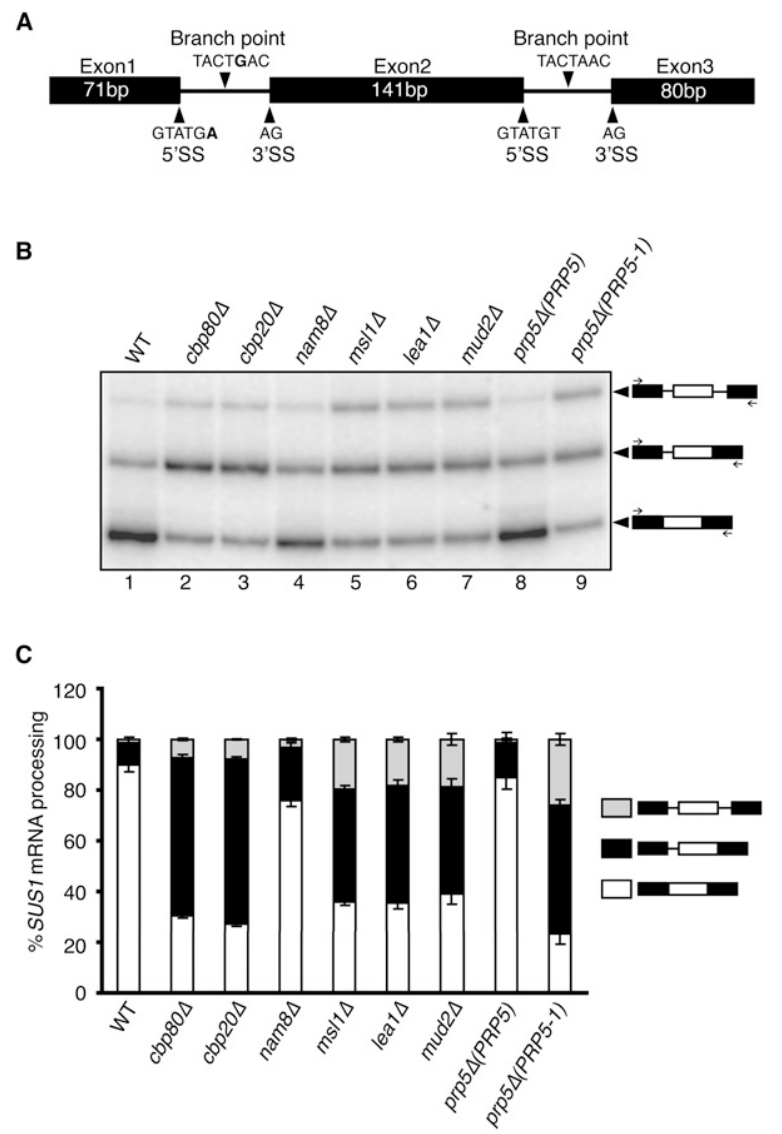

FIGURE 6. Cap binding complex mutants show a unique pattern of splicing defects for the SUS1 gene. (A) Schematic of the SUS1 gene with splice sites indicated. Nonconsensus variations in sequence are in bold. (B) Analysis of SUS1 splicing defects by reverse transcription followed by radioactive PCR in different splicing mutants. A stick diagram depiction of the spliced products is shown to the right of the gel, and the position of the primers that were used to analyze the products is indicated by the small arrow on the stick diagram. $(C)$ Quantitative analysis of SUS1 splicing defects in each mutant is presented as a bar diagram. Each bar represents the average of three independent experiments, and the error bars represent the standard errors of the mean.

(Fortes et al. 1999) and Mud2 (Fortes et al. 1999). Nam8 is a component of the U1 snRNP (Gottschalk et al. 1998) and is involved in efficient $5^{\prime}$ splice site recognition, particularly at noncanonical $5^{\prime}$ splice site sequences (Puig et al. 1999). Mud2 is a component of the yeast commitment complex and interacts with the branchpoint binding protein (BBP) to support bridging interactions between the $5^{\prime}$ splice site and the branchpoint (Abovich and Rosbash 1997). Msl1, Lea1, and Prp5 are all components of the U2 snRNP, which associates with the branchpoint sequence of the pre-mRNA.

Similar to our observations for $c b c \Delta$, we observed a decrease in fully spliced SUS1 mRNA for mud2A, msl1s, lea $1 \Delta$, and prp5-1 (only at the nonpermissive temperature) (Fig. 6B). There was a greater ratio of SUS1 pre-mRNA (in which neither intron was removed) to partially spliced 
SUS1 product in these mutants relative to $c b c \Delta$, however, demonstrating that deletion of the cap binding complex affects the splicing of SUS1 differently than deletion of other splicing mutants. Surprisingly, nam $8 \Delta$ cells showed a nearly undetectable change in splicing relative to WT (Fig. 6B). The finding that SUS1 splicing in nam8s is comparable to WT, while the branchpoint recognition factors show severe splicing defects, suggests that proper branchpoint recognition is critical for proper SUS1 splicing, although additional experiments with other, essential mutant U1 snRNP proteins are required to confirm this.

Furthermore, the greater accumulation of the single intron-containing pre-mRNA when $C B P 20$ or $C B P 80$ was deleted compared with deletion of any of the other splicing factors (Fig. 6B,C), supports previous suggestions that the $\mathrm{CBC}$ is primarily required for removal of the $5^{\prime}$ cap proximal intron (Inoue et al. 1989; Lewis et al. 1996), while the other splicing factors are required for splicing of both introns. These results also correlate with the previously published large-scale analysis of splicing in yeast using splicing-specific microarrays in which cap binding complex deletion mutants cluster differently than nam $8 \Delta$, mud2 2 , and mslis (Clark et al. 2002). Multiple independent experiments revealed that, for the partially spliced premRNA, there was accumulation of only first intron-containing transcripts (data not shown), consistent with our observations that only the first intron of SUS1 transcripts has weak splicing signals.

Nonetheless, not all genes containing two introns are dependent on the $\mathrm{CBC}$ for the removal of the first intron. We tested a second two-intron gene, DYN2, and found no splicing defect in the absence of the $\mathrm{CBC}$ (data not shown). Since not all genes containing two introns are dependent on an intact $\mathrm{CBC}$, we hypothesized that the noncanonical splice sites in the first intron rendered SUS1 splicing most dependent on the CBC. Previous studies report strong splicing defects in genes with suboptimal 5' splice sites and branchpoint sequences (Fortes et al. 1999). Since branchpoint-interacting proteins, but not the U1 snRNP protein, lead to missplicing, we suspect that the noncanonical branchpoint is a particularly important determinant of intron inclusion in the $\mathrm{CBC}$ deletion. In support of this, splicing of another gene with the same $5^{\prime}$ splice site as SUS1, GCR1, is unaffected in a CBC deleted strain.

\section{Expression of mature SUS1 mRNA correlates with Sus1 protein levels and cellular H2B ubiquitination}

Sus1 protein levels were analyzed for each splicing mutant by Western blot. As expected, there was almost no change in protein levels in the nam8s strain, but deletion of MUD2, MSL1, or LEA1 resulted in severely reduced levels of Sus1 protein (Fig. 7A). The levels of ub-H2B were also analyzed in each of these strains, and the H2B ubiquitination showed a direct correlation with the SUS1 splicing and

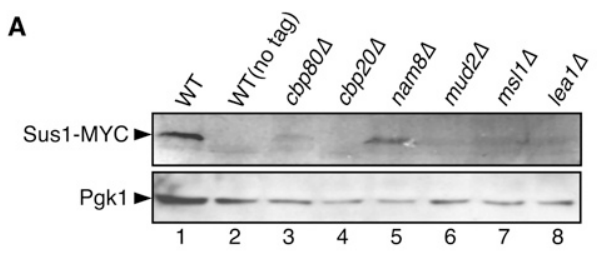

B
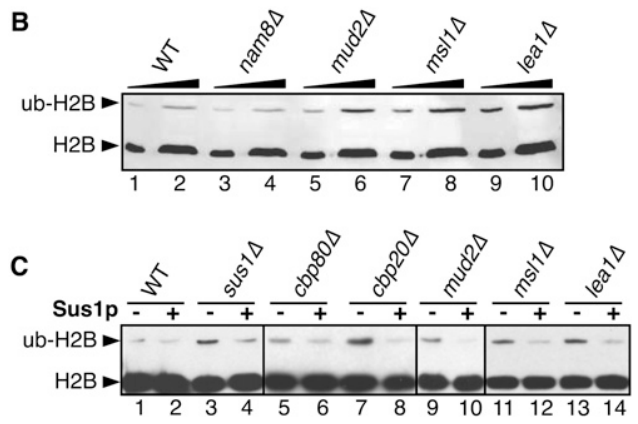

FIGURE 7. Splicing mutants affect Sus1 protein levels and histone H2B ubiquitination via their effect on SUS1 mRNA levels. (A) Western blot analysis of Sus1 levels in splicing mutants. Westerns were performed as described in Figure 5. (B) Western blot analysis of histone $\mathrm{H} 2 \mathrm{~B}$ ubiquitination. Western blotting was performed as described in Figure 4.(C) Western blot analysis of $\mathrm{H} 2 \mathrm{~B}$ ubiquitination upon expression of SUS1 cDNA. "-" Indicates the absence of the SUS1 cDNA; "+" indicates its presence.

Sus1 protein results (Fig. 7B). Western blot analysis revealed no increase in ub-H2B levels in nam8 8 compared with WT (Fig. 7B), whereas the $m u d 2 \Delta$, msl1s, and leals strains showed increases in ub-H2B levels relative to WT (Fig. 7B).

Finally, the model presented here of the role for premRNA splicing in $\mathrm{H} 2 \mathrm{~B}$ ubiquitination predicts that expression of SUS1 cDNA should suppress the overubiquitination phenotype observed with the splicing mutants and restore normal levels of H2B ubiquitination. This is precisely what we observed. Strains deleted of MUD2, MSL1, LEA1, and the $\mathrm{CBC}$ all showed elevated levels of $\mathrm{H} 2 \mathrm{~B}$ ubiquitination (Figs. 4, 7B), and expression of the SUS1 cDNA rescues the overubiquitination defect caused by improper SUS1 splicing (Fig. 7C). Expression of the cDNA has no effect on ubiquitination in wild-type cells, indicating that the lowered ubiquitination levels that are observed in the mutants are caused, specifically, by suppression of their defective splicing. Expression of the SUS1 cDNA also suppresses the overubiquitination caused by deletion of SUS1. These results demonstrate that splicing mediated regulation of Sus1 protein levels directly determines the level of $\mathrm{H} 2 \mathrm{~B}$ ubiquitination.

\section{Splicing mutants do not show the same genetic interactions with the ub-H2B machineries as the CBC}

Since deletions of CBP80, CBP20, MSL1, LEA1, and MUD2 all lead to similar effects on Sus1 protein levels and histone $\mathrm{H} 2 \mathrm{~B}$ ubiquitination, we predicted that they might all have similar genetic interactions with the $\mathrm{H} 2 \mathrm{~B}$ ubiquitination 
and deubiquitination machineries. To our surprise, this is not what we observed. While deletion of BRE1 suppresses the slow growth phenotype of the $c b c \Delta$ strains, the slow growth of mslls and lea1s strains was unaffected in the absence of this $\mathrm{H} 2 \mathrm{~B}$ ubiquitin ligase factor at $25^{\circ} \mathrm{C}$. At $30^{\circ} \mathrm{C}$, there was a mild, but reproducible synthetic growth defect (Table 1). These phenotypes are quite distinct from the growth observed when deletion of the $\mathrm{CBC}$ is combined with deletion of BRE1. There was no change in the growth of strains deleted of NAM8 or MUD2 in the absence of $B R E 1$. Moreover, the synthetic growth defect observed when $c b c \Delta$ is combined with deletion of UBP8 was not recapitulated with the other double mutants (Table 1; FQ Gunderson and TL Johnson, in prep.). These results demonstrate that the $\mathrm{CBC}$ is particularly important for establishing the proper state of $\mathrm{H} 2 \mathrm{~B}$ ubiquitination in the cell, and it may have roles in addition to effects on SUS1 splicing that contribute to proper ubiquitination of H2B (see Discussion).

\section{DISCUSSION}

The studies presented here provide insights into the intersection of two critical aspects of gene expression: premRNA splicing and histone modification. Here we show that (1) pre-mRNA splicing plays a critical role in gene expression by regulating proper chromatin modification; and (2) the cap binding complex function in splicing regulates transcription at least in part by ensuring proper function of the ubiquitin protease machinery.

In the absence of specific splicing machineries, SUS1, a gene encoding a component of the ubiquitin protease machinery, is improperly spliced (Fig. 6), Sus1 protein levels decrease dramatically (Figs. 5, 7A), and histone H2B ubiquitin proteolysis fails to occur, resulting in increased levels of ub-H2B (Figs. 4, 7B). When the cap binding complex, which is required for proper splicing of SUS1, is deleted, then, cells are unable to respond to specific changes

TABLE 1. Effect of BRE1 or UBP8 deletion on growth phenotypes of splicing mutants

\begin{tabular}{|c|c|c|}
\hline Strain & $25^{\circ} \mathrm{C}$ & $30^{\circ} \mathrm{C}$ \\
\hline cbp80s bre1s & Suppression & Suppression \\
\hline cbp20s bre1s & Suppression & Suppression \\
\hline nam8s bre1s & No effect & No effect \\
\hline mud2s bre $1 \Delta$ & No effect & No effect \\
\hline$m s / 1 \Delta$ bre $1 \Delta$ & No effect & Mild growth defects \\
\hline lea1s bre1s & No effect & Mild growth defects \\
\hline cbp804 ubp8s & $\begin{array}{l}\text { Synthetic } \\
\text { growth defects }\end{array}$ & $\begin{array}{l}\text { Synthetic } \\
\text { growth defects }\end{array}$ \\
\hline cbp20s ubp8s & $\begin{array}{l}\text { Synthetic } \\
\text { growth defects }\end{array}$ & $\begin{array}{l}\text { Synthetic } \\
\text { growth defects }\end{array}$ \\
\hline nam8s ubp8s & No effect & No effect \\
\hline mud2s ubp $8 \Delta$ & No effect & No effect \\
\hline ms/1s ubp8s & No effect & No effect \\
\hline lea1s ubp8s & No effect & No effect \\
\hline
\end{tabular}

in environmental conditions, such as increasing arginine levels, due to increased ub-H2B (Fig. 3). Global changes in expression of other intronless genes upon deletion of the CBC (Fig. 2) suggest that CBC-dependent splicing of SUS1 plays a critical role in regulating the overall gene expression program of the cell.

SUS1 is one of only a handful of yeast genes with multiple introns. Since the first intron branchpoint and $5^{\prime}$ splice site contain nonconsensus sequences, SUS1 splicing is extremely sensitive to the activity of factors involved in proper recognition of these sequences. Hence, it is not surprising that deletion of the CBC (which is involved in both U1 and triple-snRNP addition) leads to the lowest level of mature message and a preponderance of transcripts for which the first intron has been specifically retained when compared with other splicing mutants examined. What is surprising is that the genetic interactions between the ub-H2B machineries and other splicing factors do not mirror those observed for the CBC (cf. Fig. 1 and Table 1). Only the growth defect of a CBC deletion strain can be suppressed by deletion of BRE1 or RAD6 at the temperatures tested here, and only the $C B P 20$ and $C B P 80$ deletions have a severe synthetic growth defect when combined with deletion of UBP8.

There are several models that could explain this difference between the $\mathrm{CBC}$ and other splicing factors. One is that the SUS1 isoform containing one intron, which is uniquely enriched when the CBC is deleted, may be functionally important. Notably, even WT cells produce some of this message (and almost no completely unspliced RNA), indicating that steady-state levels of this product are stable enough to be identified. Finding a role for this partially spliced product would provide some of the first evidence of a function for alternatively spliced isoforms in S. cerevisiae. We are currently testing this hypothesis experimentally.

A second model is that the cap binding complex may have additional roles in establishing the proper state of histone modification. Consistent with this, we observe both genetic and physical interactions between the CBC and Bur2, which has been shown to phosphorylate Rad6 (Wood et al. 2005). Furthermore, we observe synthetic lethality when we combine deletions of PAF complex components or the histone variant, $H T Z 1$, with either $c b p 80 \Delta$ or $c b p 20 \Delta$ (MA Hossain and TL Johnson, in prep.).

Expression of the CBC is sensitive to a variety of cellular conditions, including progression into stationary phase, nitrogen depletion, and heat shock (Gasch et al. 2000), all of which are conditions under which cells undergo a dramatic shift in gene expression. In light of our studies demonstrating that the yeast cap binding complex is crucial to maintaining proper ubiquitination of numerous genes (Fig. 2), fluctuations in the steady-state levels of the CBC provide the cell with an elegant mechanism by which to regulate gene transcription and, perhaps, other gene expression reactions. 
Previous studies support a fundamental role for splicing and the regulated activity of splicing factors in regulating translation (Pleiss et al. 2007a,b). Since SUS1 is not a highly expressed gene like the components of the translation machinery, it is likely that Sus1 levels are even more sensitive to subtle changes in splicing. Moreover, since Sus1 has recently been shown to associate at the nuclear pore with the mRNA export machinery (Rodriguez-Navarro et al. 2004), it is likely that defective SUS1 splicing that generates either unspliced or partially spliced RNA has farreaching effects on gene expression. It is interesting to note that, out of the five genes for which expression not only increases the most upon deletion of CBP80, but also is repressed in a cbp80 $h t b 1 K 123 R$ double mutant, three of these show an equally significant increase in a SUS1 deletion strain (greater than twofold) (Rodriguez-Navarro et al. 2004). Since Sgf11 stabilizes Ubp8 interaction with the SAGA complex (Lee et al. 2005), it is also possible that its decrease, along with Sus1 (Fig. 5), may release the ubiquitin protease for other SAGA-independent activities.

The specific effect of the CBC on SUS1 splicing addresses long-standing questions about the general role of the cap binding complex in pre-mRNA splicing. Factors that are important for commitment complex formation, when the bridge between the $5^{\prime}$-end of the intron and the branchpoint is formed (e.g., Mud2), and those involved in branchpoint recognition by the U2 snRNP (Lea1, Msl1, and Prp5) severely affect SUS1 splicing by diminishing splicing of both introns. Meanwhile, a component of the U1snRNP involved in $5^{\prime}$ splice site recognition (Nam8) has no effect on splicing of SUS1. Another gene (GCR1) with the same 5' splice site sequence as SUS1 (GTATGA) shows no splicing defect when the CBC is deleted (data not shown). We have also examined the splicing of another gene containing two introns, DYN2, and deletion of the CBC does not affect splicing of either intron, indicating that not all cap proximal introns of two-intron genes are dependent on the CBC. Taken together, these data suggest that the CBC effect on SUS1 splicing may be due to a function in proper branchpoint recognition. Although the relationship between the $\mathrm{CBC}$ and the $5^{\prime}$ splice site has been characterized extensively (Colot et al. 1996; Lewis et al. 1996), a role in downstream events (such as branchpoint recognition) has been suggested but is poorly understood (O'Mullane and Eperon 1998; Fortes et al. 1999). These studies reinforce that the CBC is likely required for steps downstream from 5 ' splice site recognition, and SUS1 is particularly dependent on splicing of its first intron because of the combination of its proximity to the cap and its noncanonical branchpoint.

These studies not only establish an unexpected connection between splicing and histone modification, but also find the connection to be critical for proper regulation of gene expression. Increased understanding of how splicing and splicing factors, including the $\mathrm{CBC}$, are regulated under a variety of cellular conditions will further elucidate the importance of splicing in regulating the overall gene expression profile in the cell.

\section{MATERIALS AND METHODS}

\section{Yeast strains}

The yeast strains used and constructed in this study are listed in Supplemental Table 1. The yeast strains used in this study are derivatives of the wild-type (WT) BY4741. Individual TAP-tagged strains and deletion strains were obtained from Open Biosystems. TAP-tagged strains with deletions were obtained by crossing and dissecting individual TAP-tagged strains and deletion strains. SUS1 was chromosomally tagged by transforming the PCR products generated by amplification from the plasmid pFA6aHISMX6 (Longtine et al. 1998). Strains were otherwise transformed with the indicated plasmid by standard techniques, and the plasmids were maintained by growth on selective media.

For growth analysis, yeast cells were grown to an $\mathrm{OD}_{600}$ of 0.5 , and 10-fold serial dilutions were spotted onto YPD or selective media plates. Plates were incubated at the temperatures indicated and grown for 2-5 d. Liquid yeast cultures for biochemical analyses were grown at $30^{\circ} \mathrm{C}$ unless otherwise indicated.

\section{Whole-genome microarray analysis}

Total RNA was isolated from $\operatorname{cbp} 80 \Delta$ and WT strains for which native $H T B 1$ was replaced with a Flag-tagged copy of either HTB1 or $h t b 1-K 123 R$ on a plasmid. Strains were grown overnight in YPD until $50-\mathrm{mL}$ cultures reached an $\mathrm{OD}_{600}$ of $0.47-0.50$.

Total RNA $(20 \mu \mathrm{g})$ was reverse-transcribed in the presence of Cy3- or Cy5-dUTP using a mixture of oligo(dT) and random hexamers as described by Clark et al. (2002). A sample from BY4741 was also included in order to distinguish genes whose expression would be significantly affected by the presence of the plasmid. The labeled cDNAs were hybridized overnight at $65^{\circ} \mathrm{C}$ to whole-genome microarrays (a generous gift from M. Ares Jr., University of California, Santa Cruz). Hybridizations were carried out in duplicate with Cy dyes reversed on the second array. Arrays were scanned and normalized as described in Burckin et al. (2005). Hierarchical clustering was carried out using Gene Cluster 3.0 (de Hoon et al. 2004) and visualized using Java Treeview (Saldanha 2004).

\section{Northern blot analysis}

To study ARG1 repression, cells were grown in SC-Arg media to induce the synthesis of $A R G 1$ transcripts. Equal numbers of cells were taken from saturated cultures and were diluted 1/100 in YPD medium. These cultures were grown to an $\mathrm{OD}_{600}$ of $\sim 1.0-1.2$ and precipitated, and total RNA was isolated using hot-phenol extraction methods. An equal amount of total RNA $(\sim 10 \mu \mathrm{g})$ was separated by denaturing agarose-formaldehyde gel electrophoresis and transferred to a Zeta probe membrane (Bio-Rad). After UV cross-linking, the membrane was processed and probed for ARG1 transcripts. The ARG1 probe was constructed by PCR amplification of genomic DNA using the primers 5'-ATGTCTAAGGGAA AAGTTTGTTTGGCTT-3' and 5' -TTACAAAGTCAACTCTTCA 
CCTTTGGTT-3' and digested with BglII. The gel-purified, 250bp fragment was labeled with $\left[\alpha-{ }^{32} \mathrm{P}\right] \mathrm{dCTP}$ using the Rediprime random labeling system (GE Healthcare). The blot was processed and exposed to a storage phosphor screen (Molecular Dynamics), followed by detection using a Typhoon PhosphorImager (Amersham Biosciences). The same blot was stripped and probed for SED1 transcripts. The SED1 probe was generated using the primers 5' -ATCAACTGTCCTATTATCTGCCGG-3' and 5' -ACCTAAAGC ACCTGGAACGACGACG-3'. ARG1 mRNA levels were normalized to SED1 mRNA, and the percent repression was calculated relative to WT cells.

\section{Western blot analysis of whole cell extract}

For the analysis of global levels of histone H2B ubiquitination, strains were transformed with pZS145 and pZS146 plasmids (Robzyk et al. 2000), expressing Flag-tagged HTB1 or Flag-tagged HTB1 with the K123R mutation, respectively. Cells were grown in SC-His media to the same $\mathrm{OD}_{600}$ (between 0.4 and 0.8 ), and whole-cell extracts were prepared from equivalent cell numbers as determined by hemocytometer. Cell pellets were resuspended in sodium dodecyl sulfate (SDS) buffer (50 mM Tris-Cl at $\mathrm{pH} 6.8$, $100 \mathrm{mM}$ BME, 2\% SDS, 0.1\% bromophenol blue, 10\% glycerol), and cells were disrupted with $0.5 \mathrm{~mm}$ glass beads (BioSpec Products, Inc.), boiling at $95^{\circ} \mathrm{C}$, and intermittent vortexing for a total of $20 \mathrm{~min}$. Following centrifugation at $13,000 \mathrm{~g}$ for $5 \mathrm{~min}$, lysate was removed from beads, aliquoted for single use, and frozen at $-20^{\circ} \mathrm{C}$. Samples were boiled prior to use, loaded in either twofold (Fig. 4B) or threefold (Fig. 4C) increasing concentration, then resolved by $15 \%$ SDS-PAGE and transferred to PVDF membrane. For detection of ubiquitinated $\mathrm{H} 2 \mathrm{~B}$, membranes were probed with mouse monoclonal $\alpha$-Flag antibody (Sigma) diluted $1: 2000$ or $1: 10,000$ in $5 \%$ nonfat milk made with $1 \times$ TBS, followed by HRP-conjugated goat anti-mouse secondary antibody (Upstate) diluted 1:3000 or 1:20,000 in 3\% nonfat milk made with $1 \times$ TBS. Chemiluminescence was detected using the ECL plus kit (Amersham) as per the manufacturer's instructions.

To determine the levels of tagged proteins, WCEs were prepared as described above and separated by $10 \%$ SDS-PAGE. To detect the TAP-tagged protein, the blot was probed with anti-TAP antibody at a 1:3000 dilution and anti-Pgk1 antibody (Invitrogen) at a 1:2000 dilution. Sus1-13MYC protein levels were detected with anti-Myc antibody (Roche) at a final concentration of 0.5 $\mu \mathrm{g} / \mathrm{mL}$. The blots were processed and evaluated as described above.

\section{Quantitative radioactive RT-PCR}

To analyze splicing of SUS1 in vivo, strains were grown to an $\mathrm{OD}_{600}$ of 0.5-0.6. Both prp5s (PRP5) and prp5s (PRP5-1) strains were grown at $30^{\circ} \mathrm{C}$ to an $\mathrm{OD}_{600}$ of $\sim 0.5$ and then shifted for $2 \mathrm{~h}$ to $37^{\circ} \mathrm{C}$ before harvesting. Total RNA was isolated as described above. cDNA was synthesized from $2 \mu \mathrm{g}$ of total RNA with a SUS1 genespecific primer, 5'-TCATTGTGTATCTACAATCTCTTCAAG-3', using Superscript II (Invitrogen). The resulting cDNA was diluted 10-fold, and $1 \mu \mathrm{L}$ of diluted cDNA was used in a $20 \mu \mathrm{L}$ PCR reaction. The primers used to amplify the SUS1 splice products $\left(5^{\prime}-\right.$ TGGATACTGCGCAATTAAAGAGT- $3^{\prime}$ and $5^{\prime}$-TCATTGTGTATC TACAATCTCTTCAAG-3') were kinased with $\left[\alpha-{ }^{32} \mathrm{P}\right]$ ATP (MP Biochemicals) using polynucleotide kinase enzyme (NEB) and purified with the P-30 column (Bio-Rad). The PCR products were separated on an $8 \%$ nondenaturing $1 \times$ TBE polyacrylamide gel, and the images were captured using a Typhoon PhosphorImager (GE Healthcare). Signals were quantitated using ImageQuant 5.2 software (Amersham Biosciences), and the presence of each SUS1 splice variant was expressed as the percent of total SUS1 RNA.

\section{Cloning and expression of SUS1 cDNA in splicing mutants}

SUS1 cDNA was synthesized from the total RNA of the WT strain using the primer 5'-CGGGCTGCAGTCATTGTGTATCTACAAT CTCTT-3' with Superscript II (Invitrogen) according to the manufacturer's instructions. The italicized letters indicate the PstI restriction site in the primer. The resulting cDNA was PCRamplified by primers $5^{\prime}$-ATGACTATGGATACTGCGCAATT-3' and 5'-CGGGCTGCAGTCATTGTGTATCTACAATCTCTT-3' and separated on an $8 \%$ polyacrylamide gel. The amplified PCR product corresponding to mRNA (lower band of the polyacrylamide gel) was cut and eluted. The promoter region of the SUS1 gene was also PCR-amplified by the primers $5^{\prime}$-GTCCAAGC TTGTCTCCTTGAATTGAGGGAAAT-3' and 5'-GTTGTATTTT GACTCTTTAATTGCGCAG-3'. The italicized letters indicate the HindIII restriction site. The SUS1 coding region was placed downstream from the endogenous promoter by the recursive PCR technique (Prodromou and Pearl 1992) and amplified by the primer pair 5'-GTCCGAATTCGTCTCCTTGAATTGAGGGAAA 'T-3' and 5'-CGGGCTGCAGTCATTGTGTATCTACAATCTCTT-3'. After verification of the sequence, SUS1 was subcloned into pRS315, transformed into yeast cells containing the pZS145 plasmid, and the ubiquitination level was assessed by Western blotting as described above.

\section{SUPPLEMENTAL MATERIAL}

Supplemental material can be found at http://www.rnajournal.org.

\section{ACKNOWLEDGMENTS}

We thank Dr. Manuel Ares Jr. for critical reading of the manuscript and for generously provided microarrays used in these studies. We also thank Dr. Mary Anne Osley for plasmids. This work was supported by an NSF CAREER award to T.L.J. (MCB0448010) and an NSF predoctoral fellowship to J.M.C.

Received January 3, 2009; Accepted April 27, 2009.

\section{REFERENCES}

Abovich N, Rosbash M. 1997. Cross-intron bridging interactions in the yeast commitment complex are conserved in mammals. Cell 89: $403-412$.

Blencowe BJ. 2006. Alternative splicing: New insights from global analyses. Cell 126: 37-47.

Briggs SD, Xiao T, Sun ZW, Caldwell JA, Shabanowitz J, Hunt DF, Allis CD, Strahl BD. 2002. Gene silencing: Trans-histone regulatory pathway in chromatin. Nature 418: 498. doi: 10.1038/ nature00970.

Burckin T, Nagel R, Mandel-Gutfreund Y, Shiue L, Clark TA, Chong JL, Chang TH, Squazzo S, Hartzog G, Ares M Jr. 2005. 
Exploring functional relationships between components of the gene expression machinery. Nat Struct Mol Biol 12: 175-182.

Cao Y, Dai Y, Cui S, Ma L. 2008. Histone H2B monoubiquitination in the chromatin of FLOWERING LOCUS C regulates flowering time in Arabidopsis. Plant Cell 20: 2586-2602.

Chang M, French-Cornay D, Fan HY, Klein H, Denis CL, Jaehning JA. 1999. A complex containing RNA polymerase II, Paflp, Cdc73p, Hprlp, and Ccr4p plays a role in protein kinase $\mathrm{C}$ signaling. Mol Cell Biol 19: 1056-1067.

Chavez S, Beilharz T, Rondon AG, Erdjument-Bromage H, Tempst P, Svejstrup JQ, Lithgow T, Aguilera A. 2000. A protein complex containing Tho2, Hpr1, Mft1 and a novel protein, Thp2, connects transcription elongation with mitotic recombination in Saccharomyces cerevisiae. EMBO J 19: 5824-5834.

Clark TA, Sugnet CW, Ares M Jr. 2002. Genomewide analysis of mRNA processing in yeast using splicing-specific microarrays. Science 296: 907-910.

Collins SR, Kemmeren P, Zhao XC, Greenblatt JF, Spencer F, Holstege FC, Weissman JS, Krogan NJ. 2007. Toward a comprehensive atlas of the physical interactome of Saccharomyces cerevisiae. Mol Cell Proteomics 6: 439-450.

Colot HV, Stutz F, Rosbash M. 1996. The yeast splicing factor Mud13p is a commitment complex component and corresponds to CBP20, the small subunit of the nuclear cap-binding complex. Genes \& Dev 10: 1699-1708.

Das B, Guo Z, Russo P, Chartrand P, Sherman F. 2000. The role of nuclear cap binding protein Cbclp of yeast in mRNA termination and degradation. Mol Cell Biol 20: 2827-2838.

de Hoon MJ, Imoto S, Nolan J, Miyano S. 2004. Open source clustering software. Bioinformatics 20: 1453-1454.

Dover J, Schneider J, Tawiah-Boateng MA, Wood A, Dean K, Johnston M, Shilatifard A. 2002. Methylation of histone H3 by COMPASS requires ubiquitination of histone H2B by Rad6. J Biol Chem 277: 28368-28371.

Fortes P, Kufel J, Fornerod M, Polycarpou-Schwarz M, Lafontaine D, Tollervey D, Mattaj IW. 1999. Genetic and physical interactions involving the yeast nuclear cap-binding complex. Mol Cell Biol 19: 6543-6553.

Gardner RG, Nelson ZW, Gottschling DE. 2005. Ubp10/Dot4p regulates the persistence of ubiquitinated histone H2B: Distinct roles in telomeric silencing and general chromatin. Mol Cell Biol 25: 6123-6139.

Gasch AP, Spellman PT, Kao CM, Carmel-Harel O, Eisen MB, Storz G, Botstein D, Brown PO. 2000. Genomic expression programs in the response of yeast cells to environmental changes. Mol Biol Cell 11: 4241-4257.

Gavin AC, Aloy P, Grandi P, Krause R, Boesche M, Marzioch M, Rau C, Jensen LJ, Bastuck S, Dumpelfeld B, et al. 2006. Proteome survey reveals modularity of the yeast cell machinery. Nature 440: 631-636.

Görnemann J, Kotovic KM, Hujer K, Neugebauer KM. 2005. Cotranscriptional spliceosome assembly occurs in a stepwise fashion and requires the cap binding complex. Mol Cell 19: $53-$ 63.

Gottschalk A, Tang J, Puig O, Salgado J, Neubauer G, Colot HV, Mann M, Seraphin B, Rosbash M, Lührmann R, et al. 1998. A comprehensive biochemical and genetic analysis of the yeast $\mathrm{U} 1$ snRNP reveals five novel proteins. RNA 4: 374-393.

Henry KW, Wyce A, Lo WS, Duggan LJ, Emre NC, Kao CF, Pillus L, Shilatifard A, Osley MA, Berger SL. 2003. Transcriptional activation via sequential histone $\mathrm{H} 2 \mathrm{~B}$ ubiquitylation and deubiquitylation, mediated by SAGA-associated Ubp8. Genes \& Dev 17: 2648 2663.

Inoue K, Ohno M, Sakamoto H, Shimura Y. 1989. Effect of the cap structure on pre-mRNA splicing in Xenopus oocyte nuclei. Genes \& Dev 3: 1472-1479.

Kao CF, Hillyer C, Tsukuda T, Henry K, Berger S, Osley MA. 2004. Rad6 plays a role in transcriptional activation through ubiquitylation of histone H2B. Genes \& Dev 18: 184-195.
Kohler A, Schneider M, Cabal GG, Nehrbass U, Hurt E. 2008. Yeast Ataxin-7 links histone deubiquitination with gene gating and mRNA export. Nat Cell Biol 10: 707-715.

Komili S, Farny NG, Roth FP, Silver PA. 2007. Functional specificity among ribosomal proteins regulates gene expression. Cell 131: 557-571.

Lee KK, Florens L, Swanson SK, Washburn MP, Workman JL. 2005. The deubiquitylation activity of Ubp8 is dependent upon Sgf11 and its association with the SAGA complex. Mol Cell Biol 25: $1173-1182$.

Lewis JD, Izaurralde E, Jarmolowski A, McGuigan C, Mattaj IW. 1996. A nuclear cap-binding complex facilitates association of U1 snRNP with the cap-proximal $5^{\prime}$ splice site. Genes \& Dev 10: $1683-1698$

Longtine MS, McKenzie A III, Demarini DJ, Shah NG, Wach A, Brachat A, Philippsen P, Pringle JR. 1998. Additional modules for versatile and economical PCR-based gene deletion and modification in Saccharomyces cerevisiae. Yeast 14: 953-961.

Matlin AJ, Clark F, Smith CW. 2005. Understanding alternative splicing: Toward a cellular code. Nat Rev Mol Cell Biol 6: 386-398.

Mutiu AI, Hoke SM, Genereaux J, Liang G, Brandl CJ. 2007. The role of histone ubiquitylation and deubiquitylation in gene expression as determined by the analysis of an HTB1(K123R) Saccharomyces cerevisiae strain. Mol Genet Genomics 277: 491-506.

$\mathrm{Ng} \mathrm{HH}$, Xu RM, Zhang Y, Struhl K. 2002. Ubiquitination of histone H2B by Rad6 is required for efficient Dot1-mediated methylation of histone H3 lysine 79. J Biol Chem 277: 34655-34657.

Oeffinger M, Wei KE, Rogers R, DeGrasse JA, Chait BT, Aitchison JD, Rout MP. 2007. Comprehensive analysis of diverse ribonucleoprotein complexes. Nat Methods 4: 951-956.

O'Mullane L, Eperon IC. 1998. The pre-mRNA 5' cap determines whether U6 small nuclear RNA succeeds U1 small nuclear ribonucleoprotein particle at $5^{\prime}$ splice sites. Mol Cell Biol 18: 7510-7520.

Osley MA, Fleming AB, Kao CF. 2006. Histone ubiquitylation and the regulation of transcription. Results Probl Cell Differ 41: 4775.

Pavri R, Zhu B, Li G, Trojer P, Mandal S, Shilatifard A, Reinberg D. 2006. Histone H2B monoubiquitination functions cooperatively with FACT to regulate elongation by RNA polymerase II. Cell 125: 703-717.

Pleiss JA, Whitworth GB, Bergkessel M, Guthrie C. 2007a. Rapid, transcript-specific changes in splicing in response to environmental stress. Mol Cell 27: 928-937.

Pleiss JA, Whitworth GB, Bergkessel M, Guthrie C. 2007b. Transcript specificity in yeast pre-mRNA splicing revealed by mutations in core spliceosomal components. PLoS Biol 5: e90. doi: 10.1371/ journal.pbio.0050090.

Prodromou C, Pearl LH. 1992. Recursive PCR: A novel technique for total gene synthesis. Protein Eng 5: 827-829.

Puig O, Gottschalk A, Fabrizio P, Seraphin B. 1999. Interaction of the U1 snRNP with nonconserved intronic sequences affects 5 ' splice site selection. Genes \& Dev 13: 569-580.

Robzyk K, Recht J, Osley MA. 2000. Rad6-dependent ubiquitination of histone H2B in yeast. Science 287: 501-504.

Rodriguez-Navarro S, Fischer T, Luo MJ, Antunez O, Brettschneider S, Lechner J, Perez-Ortin JE, Reed R, Hurt E. 2004. Sus1, a functional component of the SAGA histone acetylase complex and the nuclear pore-associated mRNA export machinery. Cell 116: 75-86.

Rondon AG, Garcia-Rubio M, Gonzalez-Barrera S, Aguilera A. 2003. Molecular evidence for a positive role of Spt4 in transcription elongation. EMBO J 22: 612-620.

Saldanha AJ. 2004. Java Treeview-extensible visualization of microarray data. Bioinformatics 20: 3246-3248.

Shema E, Tirosh I, Aylon Y, Huang J, Ye C, Moskovits N, RaverShapira N, Minsky N, Pirngruber J, Tarcic G, et al. 2008. The histone H2B-specific ubiquitin ligase RNF20/hBRE1 acts as a putative tumor suppressor through selective regulation of gene expression. Genes \& Dev 22: 2664-2676. 
Shukla A, Bhaumik SR. 2007. H2B-K123 ubiquitination stimulates RNAPII elongation independent of H3-K4 methylation. Biochem Biophys Res Commun 359: 214-220.

Sun ZW, Allis CD. 2002. Ubiquitination of histone H2B regulates H3 methylation and gene silencing in yeast. Nature 418: 104-108.

Tanny JC, Erdjument-Bromage H, Tempst P, Allis CD. 2007. Ubiquitylation of histone $\mathrm{H} 2 \mathrm{~B}$ controls RNA polymerase II transcription elongation independently of histone $\mathrm{H} 3$ methylation. Genes \& Dev 21: 835-847.

Turner SD, Ricci AR, Petropoulos H, Genereaux J, Skerjanc IS, Brandl CJ. 2002. The E2 ubiquitin conjugase Rad6 is required for the ArgR/Mcml repression of ARG1 transcription. Mol Cell Biol 22: 4011-4019.

Uemura H, Pandit S, Jigami Y, Sternglanz R. 1996. Mutations in GCR3, a gene involved in the expression of glycolytic genes in Saccharomyces cerevisiae, suppress the temperature-sensitive growth of hpr1 mutants. Genetics 142: 1095-1103.

Weake VM, Workman JL. 2008. Histone ubiquitination: Triggering gene activity. Mol Cell 29: 653-663.

Weake VM, Lee KK, Guelman S, Lin CH, Seidel C, Abmayr SM, Workman JL. 2008. SAGA-mediated H2B deubiquitination controls the development of neuronal connectivity in the Drosophila visual system. EMBO J 27: 394-405.
Wong CM, Qiu H, Hu C, Dong J, Hinnebusch AG. 2007. Yeast cap binding complex impedes recruitment of cleavage factor IA to weak termination sites. Mol Cell Biol 27: 6520-6531.

Wood A, Krogan NJ, Dover J, Schneider J, Heidt J, Boateng MA, Dean K, Golshani A, Zhang Y, Greenblatt JF, et al. 2003a. Bre1, an E3 ubiquitin ligase required for recruitment and substrate selection of Rad6 at a promoter. Mol Cell 11: 267-274.

Wood A, Schneider J, Dover J, Johnston M, Shilatifard A. 2003b. The Paf1 complex is essential for histone monoubiquitination by the Rad6-Brel complex, which signals for histone methylation by COMPASS and Dotlp. J Biol Chem 278: 34739-34742.

Wood A, Schneider J, Dover J, Johnston M, Shilatifard A. 2005. The Bur1/Bur2 complex is required for histone H2B monoubiquitination by Rad6/Brel and histone methylation by COMPASS. Mol Cell 20: 589-599.

Wyce A, Xiao T, Whelan KA, Kosman C, Walter W, Eick D, Hughes TR, Krogan NJ, Strahl BD, Berger SL. 2007. H2B ubiquitylation acts as a barrier to Ctk1 nucleosomal recruitment prior to removal by Ubp8 within a SAGA-related complex. Mol Cell 27: 275-288.

Xiao T, Kao CF, Krogan NJ, Sun ZW, Greenblatt JF, Osley MA, Strahl BD. 2005. Histone H2B ubiquitylation is associated with elongating RNA polymerase II. Mol Cell Biol 25: 637-651. 

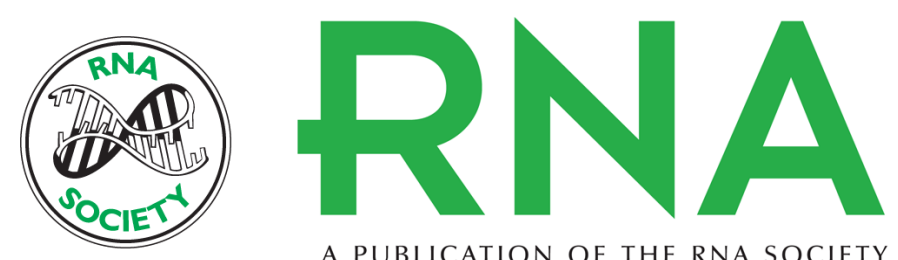

A PUBLICATION OF THE RNA SOCIETY

\section{The cap binding complex influences H2B ubiquitination by facilitating splicing of the SUS1 pre-mRNA}

Munshi Azad Hossain, Julia M. Claggett, Tiffany Nguyen, et al.

RNA 2009 15: 1515-1527 originally published online June 26, 2009

Access the most recent version at doi:10.1261/rna.1540409

\section{Supplemental http://rnajournal.cshlp.org/content/suppl/2009/06/26/rna.1540409.DC1 \\ Material}

References This article cites 56 articles, 29 of which can be accessed free at: http://rnajournal.cshlp.org/content/15/8/1515.full.html\#ref-list-1

\section{License}

Email Alerting Receive free email alerts when new articles cite this article - sign up in the box at the Service top right corner of the article or click here.

To subscribe to $R N A$ go to:

http://rnajournal.cshlp.org/subscriptions 